\title{
RESPON BIBIT KELAPA SAWIT ATAS PEMBERIAN PUPUK ORGANIK PADA TANAH GAMBUT DI KALIMANTAN TENGAH (Palm oil seedling response of organic fertilizer on peat soil in Central Kalimantan)
}

\author{
Sustiyah $^{1 *}$; Sulistiyanto, Y. ${ }^{1)}$; Damanik, Z. ${ }^{1)}$ \\ ${ }^{1)}$ Prodi Agroteknologi, Jurusan Budidaya Pertanian Fakultas Pertanian Universitas Palangka Raya \\ Telpon : $082156005763 *$ Corresponding author : sustiyah@agr.upr.ac.id
}

Disetujui : 23/04/2018_ Disetujui : 06/08/2018

\begin{abstract}
The purpose of this study was to determine response of main nursery palm seedlings for application of organic fertilizers on soil peat. The experiment used completely randomized factorial design consisting of two factors. The first factor was petroganik fertilizers $(\mathrm{P})$ consists of four levels: $\mathrm{Po}=$ control or no petroganik $(0 \mathrm{~kg} /$ plants $), \mathrm{P} 1=$ petroganik $0,5 \mathrm{~kg} / \mathrm{plants}, \mathrm{P} 2=$ Petrogenik $1 \mathrm{~kg} / \mathrm{plants} ; \mathrm{P} 3=$ Petrogenik $2 \mathrm{~kg} / \mathrm{plans}$. The second factor was bokhasi kayambang fertilizers $(\mathrm{K})$ consists of four levels: Ko $=$ control or no bokhasi kayambang $(0 \mathrm{~kg} / \mathrm{plants}) ; \mathrm{K} 1=$ Bokhasi Kayambang 0,5 kg/plants; K2 = Bokhasi Kayambang 1 kg/plants; $\mathrm{K} 3=$ Bokhasi Kayambang 2 $\mathrm{kg} / \mathrm{plants}$. The each treatment was replicated five times. Observed variables were plant height, number of leaf midrib, number of primary root and length of primary root. Results showed that interaction between the application of petroganik fertilizers $2 \mathrm{~kg} / \mathrm{plants}$ and bokhasi kayambang fertilizers $1 \mathrm{~kg} /$ plants $(\mathrm{P} 3 \mathrm{~K} 2)$, respond positively to the growth of oil palm seedlings main nursery whith soil $\mathrm{pH} 5,95$. This treatment produced the highest plant height, the largest number of leaf midrib, the best root number and length of primary root.
\end{abstract}

Key word : oil palm seedling, rubber waste liquid, fertilizer

\begin{abstract}
ABSTRAK
Tujuan penelitian ini adalah untuk mengetahui respon bibit kelapa sawit main nursery terhadap pemberian pupuk organik pada tanha gambut. Penelitian dilakukan menggunakan Rancangan Acak Lengkap faktorial yang terdiri dari dua faktor perlakuan pupuk organik. Faktor pertama adalah pupuk petrogenik $(\mathrm{P})$ yang terdiri dari 4 taraf, yaitu: $\mathrm{Po}=$ kontrol $0 \mathrm{~kg} /$ tanaman; $\mathrm{P} 1=$ Petrogenik 0,5 kg/tanaman; $\mathrm{P} 2$ = Petrogenik $1 \mathrm{~kg} /$ tanaman; $\mathrm{P} 3$ = Petrogenik $2 \mathrm{~kg} /$ tanaman. Faktor kedua, pupuk bokhasi kayambang $(\mathrm{K})$, terdiri 4 taraf, yaitu: $\mathrm{Ko}=$ kontrol $0 \mathrm{~kg} / \mathrm{tanaman}$; $\mathrm{K} 1=$ Bokhasi Kayambang 0,5 kg/tanaman; K2 = Bokhasi Kayambang 1 kg/tanaman; K3 = Bokhasi Kayambang $2 \mathrm{~kg} / \mathrm{tanaman}$. Ulangan dilakukan sebanyak 5 kali. Variabel yang diamati tinggi tanaman, jumlah pelepah daun, jumlah akar primer, panjang akar primer, Hasil penelitian menunjukkan bahwa interaksi antara pemberian pupuk petrogenik $2 \mathrm{~kg} / \operatorname{tanaman}$ dan bhokasi kayambang $1 \mathrm{~kg} / \mathrm{tanaman}$ (P3K2), memberikan respon yang positif terhadap pertumbuhan bibit kelapa sawit main nursery dengan $\mathrm{pH}$ tanah 5,95, memiliki tinggi tanaman tertinggi dan jumlah pelepah daun terbanyak, jumlah dan panjang akar primer terbaik.
\end{abstract}

Kata kunci : Bibit kelapa sawit, pupuk organik, tanah gambut 


\section{PENDAHULUAN}

Kelapa sawit (Elaeis guineensis jacq) merupakan komoditas perkebunan yang mempunyai nilai ekonomi tinggi, karena dapat menghasilkan minyak nabati untuk bahan bakar, alat kosmetik, bahan baku sabun, margarin, minyak goreng dan lainnya (Setyamidjaja, 1991; Yusof, 2007; Nikoloyuk et al., 2010; Krystof et al., 2012; Ludin et al., 2014; Ohimain dan Izah, 2014; Oosterveer, 2015)

Perkembangan perkebunan swasta kelapa sawit di Kalimantan Tengah saat ini, menunjukkan kemajuan yang semakin pesat. Luas perkebunan sawit yang sudah ditanami di Kalimantan Tengah sekitar 702.273,33 hektar (BPS Kalteng, 2007).

Pengeloaan tanaman sawit diawali dengan kegiatan pembibitan. Keberhasilan dalam budidaya tanaman kelapa sawit sangat ditentukan oleh keberhasilan kegiatan pembibitan. Pembibitan memberikan kontribusi yang nyata terhadap pertumbuhan dan perkembangan tanaman. Pembibitan kelapa sawit perlu perhatian serius, tetap dan terus menerus hingga umur $1-1,5$ tahun. Produksi awal di lapangan berkorelasi nyata dengan luas daun pada periode tanaman belum menghasilkan. Kondisi ini yang sangat ditentukan oleh keadaan pembibitan yang baik (Pahan, 2006).

Budidaya tanaman sawit, khususnya di pembibitan baik Pre Nursery dan Main Nursery sering mengalami hambatan karena dampak dan mahalnya harga pupuk dan pestisida menyebabkan petani kurang bersemangat dalam berbudidaya tanaman sawit, sehingga perlu diupayakan pupuk alternatif yang dapat mengurangi ketergantungan terhadap produk pupuk dan pestisida anorganik. Pembibitan Pre Nursery dan Main Nursery memerlukan media tanam yang cukup nutrisi agar tanaman tumbuh subur. Rendahnya unsur hara dalam tanah disebabkan oleh tanah secara terus menerus digunakan tanpa mengembalikan biomassa (Hakim, 1985).

Perhatian masyarakat Kalimantan Tengah dalam berusahatani masih kurang, hal ini terbukti dari pertumbuhan yang dikelola selama ini belum memberikan hasil yang optimal. Hal ini terjadi karena kondisi lahan kritis dan kurangnya ketersediaan hara serta makin mahalnya pupuk anorganik dan pestisida. Di samping itu, residu pemakaian pestisida dapat berdampak negatif terhadap lingkungan dan kesehatan, serta dapat mengganggu ekosistem lahan pertanian baik secara makro atau mikro (Munir,1996).

Usaha untuk meningkatkan pertumbuhan tanaman dengan pemupukan sering terhambat oleh mahalnya harga pupuk buatan bahkan kadang pupuk tidak tersedia. Terlebih di Kalimantan Tengah cukup jauh dari pabrik pupuk buatan. Penggunaan pupuk buatan NPK secara terus-menerus dapat menipiskan ketersediaan hara mikro seperti seng, besi, tembaga, mangan, molibdenum, dan boron yang mengakibatkan tanaman menjadi kerdil, produksi menurun, dan rentan terhadap hama/penyakit (Ruskandi, 2006).

Upaya-upaya untuk meningkatkan pertumbuhan bibit kelapa sawit main nursery pada lahan kritis di Kalimantan Tengah yang tingkat kesuburan tanahnya rendah dan masam adalah pemberian pupuk organik petroganik dan bokhasi kayambang. Pupuk organic ini tersedia di Kalimantan Tengah dalam jumlah yang melimpah. Hasil-hasil penelitian yang dilakukan oleh para peneliti di berbagai kondisi menunjukkan bahwa aplikasi pupuk organik dapat memperbaiki karakteristik fisika, kimia dan biologi tanah; dan dapat memperbaiki kualitas tanah untuk pertumbuhan dan produksi tanaman (Kong et al., 2005; Rudrappa et al., 2006; Su et al., 2006; Hai et al., 2010; Liu et al., 2010; Herencia et al., 2011; Ghosh et al., 2012; Maltas et al., 2013; Zhou et al., 2013; Afandi, Siswanto dan Nuraini, 2015; Lawenga, Hasanah dan Widjajanto, 2015; Nuro, Priadi, dan Mulyaningsih, 2016; Rong et al., 2016; Menšík et al., 2018).

Berdasarkan latar belakang permasalahan tersebut, maka perlu dilakukan penelitian respon pembibitan tanaman kelapa sawit main nursery terhadap pemberian pupuk organik pada tanah gambut di Kalimantan Tengah. 


\section{BAHAN DAN METODE}

Penelitian dilaksanakan di halaman belakang Laboratorium Analitik Universitas Palangka Raya (UPR), Kota Palangka Raya. Analisis unsur hara pupuk organik (pupuk petoganik dan bokhasi kayambang) dan analisis tanah sebelum dan sesudah dilakukan pemupukan dilakukan di Laboratorium Dasar dan Analitik Universitas Palangka Raya.

Bahan yang digunakan dalam ujicoba lapangan ini adalah: paket pupuk organik (pupuk petroganik), bokhasi kayambang berbasis dekomposer EM4 (kayambang, gula, EM4, dan air), dedak, polybag ukuran $40 \mathrm{x}$ $50 \mathrm{~cm}$, bibit kelapa sawit main nursery varietas Lumsum, kapur dolomit, dan bahan lainnya yang menunjang penelitian. Peralatan yang digunakan dalam penelitian ini meliputi cangkul, parang, spreyer, gembor, timba, thermometer, $\mathrm{pH}$ meter, kayu, camera, meteran, terpal ukuran $4 \times 6 \mathrm{~m}$, timbangan, alat tulis, karung goni/terpal, peralatan laboratorium untuk analisis tanah, dan alat bantu lainnya yang menunjang penelitian ini.

Rancangan yang digunakan adalah Rancangan Acak Lengkap faktorial yang terdiri dari dua faktor perlakuan pupuk organik. Faktor pertama adalah pemberian pupuk petrogenik $(\mathrm{K})$ yang terdiri dari 4 taraf, yaitu: $\mathrm{Po}=$ kontrol $0 \mathrm{~kg} /$ tanaman; $\mathrm{P} 1=$ Petrogenik 0,5 kg/tanaman; $\mathrm{P} 2=$ Petrogenik $1 \mathrm{~kg} /$ tanaman; $\mathrm{P} 3=$ Petrogenik 2 $\mathrm{kg} /$ tanaman. Faktor kedua, pemberian pupuk bokhasi kayambang (K), terdiri 4 taraf, yaitu: Ko $=$ kontrol 0 kg/tanaman; $\mathrm{K} 1$ = Bokhasi Kayambang 0,5 kg/tanaman; K2 = Bokhasi Kayambang $1 \mathrm{~kg} /$ tanaman;K3 = Bokhasi Kayambang $2 \mathrm{~kg} /$ tanaman. Masing-masing kombinasi perlakuan diulang 5 kali (2 ulangan untuk pengamatan destruktif) sehingga diperoleh 80 satuan percobaan.

Media pembibitan yang digunakan adalah tanah gambut yang diambil dari di sekitar kampus. Tanah yang digunakan sebanyak $6 \mathrm{~kg}$ polybag ${ }^{-1}$ diberi kapur dolomit dengan dosis 4 ton ha ${ }^{-1}\left(50 \mathrm{~g}\right.$ polybag $\left.^{-1}\right)$ dan pupuk organik (pupuk ptroganik dan bhokasi kayambang) sesuai perlakuan, dimasukkan ke dalam polybag berukuran $40 \times 50 \mathrm{~cm}$. Pemberian pupuk oganik (petrogenik dan bokhasi kayambang) dilakukan 1 kali pada saat persiapan media tanam sesuai masingmasing paket perlakuan yang sudah ditentukan dengan cara mencampur keduanya (tanah+kapur+pupuk organik). Bibit kelapa sawit main nursery yang digunakan berumur 5 bulan. Penanaman dilakukan pada pagi atau sore hari pada saat matahari tidak terlalu terik, setelah penanaman selesai, dilakukan penyiraman. Penyiraman selanjutnya dilakukan 2 kali sehari yaitu pagi dan sore hari tergantung keadaan tanah dan cuaca selama 3 bulan (Tjahjadi, 1991). Pupuk majemuk NPK mutiara sebagai pupuk dasar diberikan dengan dosis $80 \mathrm{~kg} / \mathrm{ha}$ atau (1 gram/tanaman), diberikan 1 kali 1 hari setelah pemindahan bibit dengan cara dibenamkan sejauh $10 \mathrm{~cm}$ dari batang tanaman. Variabel yang diamati meliputi: tinggi tanaman dan jumlah pelepah daun umur 2, 4, 6, 8, 10, dan 12 minggu setelah tanam (MST) di pembibitan main nursery, jumlah dan panjang akar primer pada umur 12 mst, analisis tanah sebelum dan sesudah pemberian pupuk organik, analisi pupuk organik (petrogenik + bokhasi kayambang setelah fermentasi).

Data hasil pengamatan dilakukan analisis ragam (uji F) pada taraf $\alpha=0,05$ dan 0,01 . Apabila perlakuan berpengaruh nyata, maka dilakukan uji nilai tengah dengan uji BNJ (Beda Nyata Jujur) taraf $\alpha=0,05$ untuk mengetahui perbedaan antar taraf perlakuan.

\section{HASIL DAN PEMBAHASAN}

\section{Tinggi Tanaman}

Respon tinggi bibit tanaman kelapa sawit main nursery akibat pemberian kombinasi pupuk organik (pupuk petroganik dengan bokhasi kayambang) pada tanah gambut dari 0 hingga 12 minggu setelah tanam disajikan pada Gambar 1.

Gambar 1 menunjukkan bahwa perlakuan tertinggi terhadap tinggi bibit kepala sawit main nursery secara keseluruhan dari umur 2 hingga 12 MST terjadi pada pemberian kombinasi pupuk petroganik $2 \mathrm{~kg} / \operatorname{tanaman}$ dan bokhasi kayambang $1 \mathrm{~kg} /$ tanaman (P3K2). Tingginya pengaruh pemberian petroganik 2 $\mathrm{kg} /$ tanaman (P3) dan bokhasi kayambang 1 
$\mathrm{kg} /$ tanaman $(\mathrm{P} 3 \mathrm{~K} 2)$ terhadap tinggi tanaman dimungkinkan petroganik dan bokhasi kayambang cukup mendukung kebutuhan pertumbuhan tinggi bibit sawit main nursery dari umur 0 hingga 12 MST. Hal ini dikarenakan kayambang merupakan tanaman air yang bersimbiose dengan mikroorganisme jenis anabaena yang dapat mengikat nitrogen dari udara. Jika biomassa kayambang digunakan sebagai pupuk organik, maka dapat mensuplai kebutuhan $\mathrm{N}$ bagi pertumbuhan tanaman khususnya tinggi tanaman. Pernyataan ini didukung dari hasil analisis $\mathrm{pH}$ di laboratorium, yakni $\mathrm{pH}$ untuk perlakuan P3K2 menunjukkan hasil yang relatif tinggi yakni 5,95. Tingginya $\mathrm{pH}$ pada perlakuan P3K2 dapat membantu proses serapan hara tersedia di dalam media tanam akibat sumbangan hara dari pemberian kombinasi kedua pupuk organik tersebut. Pupuk organik, seperti petroganik dan bokhasi kayambang, mempunyai fungsi penting dalam tanah yaitu untuk dapat menggemburkan lapisan tanah permukaan (topsoil), meningkatkan populasi jasad renik (Lee, 2010), memperbaiki daya serap dan daya simpan air tersedia (Liu et al., 2013), dapat meningkatkan kesuburan tanah dan memperbaiki kualitas tanah bagi pertumbuhan tanaman (Muslihat, 2009; Zhao et al., 2009; Willekens et al., 2014; Sustiyah et al., 2015).

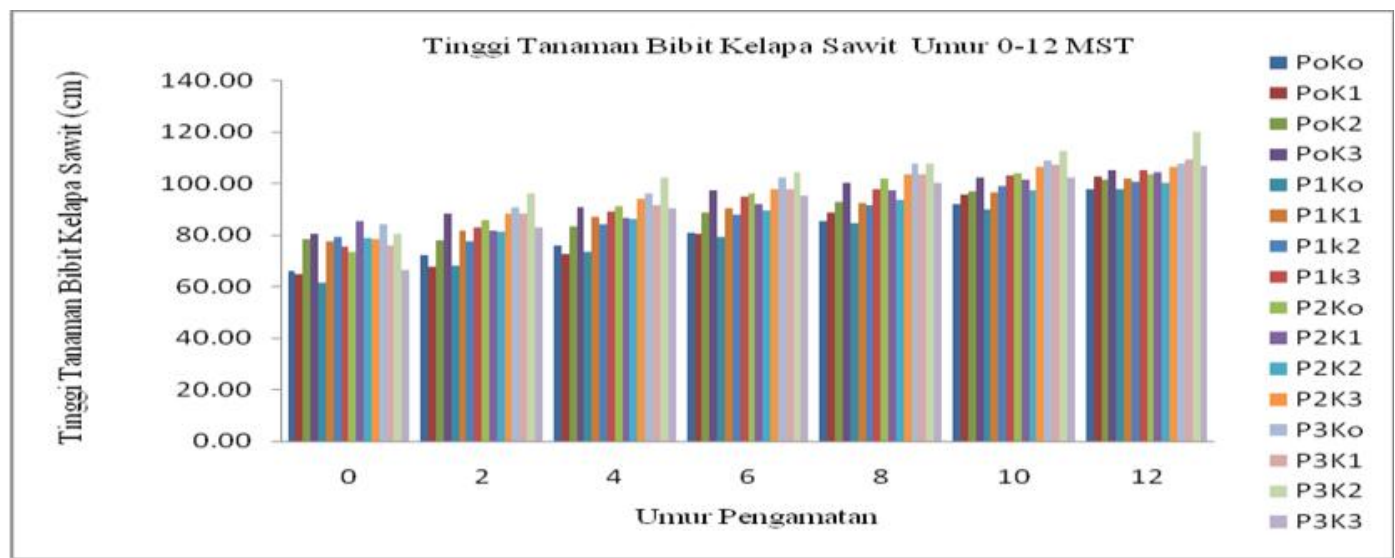

Gambar 1. Respon tinggi bibit kelapa sawit main nursery umur 0-12 MST atas pemberian kombinasi pupuk petroganik dan bokhasi kayambang

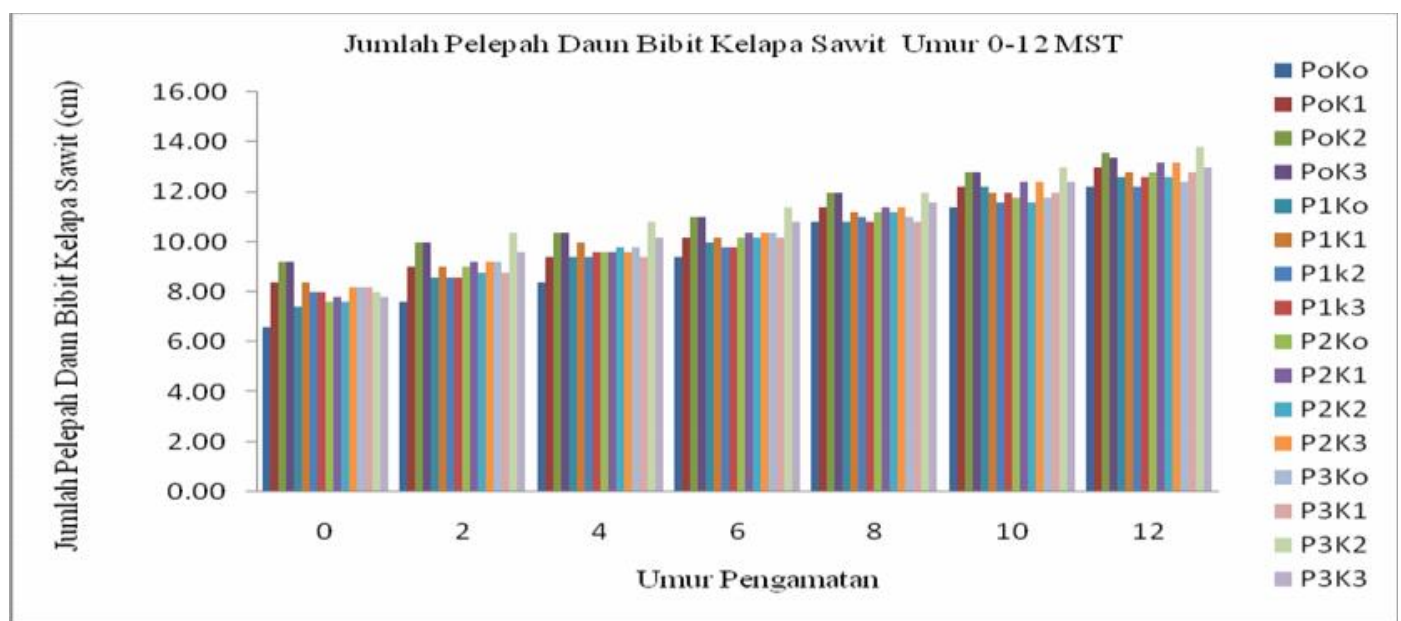

Gambar 2. Respon jumlah pelepah daun bibit kelapa sawit umur 0 hingga 12 MST akibat pemberian kombinasi pupuk petroganik dengan bokhasi kayambang. 


\section{Jumlah Pelepah Daun}

Respon jumlah pelepah daun kelapa sawit main nursery akibat pemberian kombinasi pupuk organik (pupuk petroganik dengan bokhasi kayambang) pada tanah gambut dari 0 hingga 12 minggu setelah tanam disajikan pada Gambar 2.

Gambar 2 menunjukkan bahwa perlakuan petroganik $2 \mathrm{~kg} / \mathrm{tanaman}$ dan Bokhasi Kayambang $1 \mathrm{~kg} / \mathrm{tanaman}$ (P3K2) menghasilkan jumlah pelepah daun terbanyak. Hal ini berarti bahwa pemberian pupuk petroganik dan bokhasi kayambang pada P3K2 relatif lebih mampu menyumbangkan hara dalam pembentukan jumlah pelepah daun. Pernyataan ini didukung oleh nilai $\mathrm{pH}$ tanah akhir pada perlakuan P3K2 meningkatkan $\mathrm{pH}$ tanah menjadi 5,95, yang berarti dengan nilai $\mathrm{pH}$ tersebut hara yang disumbangkan cukup mendukung pembentukan jumlah pelepah daun bibit kelapa sawit main nursery umur 2 hingga 12 MST.

Pemberian petroganik dan bokhasi kayambang relatif cukup menyumbangkan hara dalam pembentukan jumlah pelepah daun, hal ini terbukti bahwa nilai rata-rata jumlah pelepah daun pada masing-masing perlakuan pemberian kombinasi petroganik dan bokhasi kayambang terjadi peningkatan jumlah pelepah daun dari umur 2 hingga 12 MST. Proses mineralisasi pupuk organik seperti petroganik (P) dan bokhasi kayambang (K) dalam tanah akan melepaskan hara tanaman yaitu $\mathrm{N}, \mathrm{P}, \mathrm{K}, \mathrm{Ca}, \mathrm{Mg}, \mathrm{S}$, serta hara mikro (DeNeve dan Hofman, 1996; Rahn et al., 2003; DeNeve et al., 2004; Chaves et al., 2007; Al-Bataina, Young dan Ranieri. 2016). Hara-hara yang dilepaskan dari pupuk organik tersebut diperlukan untuk menambah ketersediaan hara dalam tanah dan mendukung pertumbuhan tanaman. Kayambang merupakan tanaman air yang bersimbiose dengan anabaena yang dapat memfiksasi N2 dari udara, sehingga biomassanya dapat dimanfaatkan sebagai pupuk organik (Rosmarkam dan Yuwono, 2002; Sustiyah, et al., 2015). Unsur hara N sangat diperlukan pertumbuhan tanaman fase vegetatif pada pertumbuhan jumlah pelepah daun dan tinggi tanaman. Adanya hara dalam tanah yang cukup dan $\mathrm{pH}$ tanah mendukung pertumbuhan tanaman, maka hara tesebut mudah diserap oleh tanaman sehingga pertumbuhan tanaman (tinggi tanaman dan jumlah pelepah) menjadi lebih baik (Iremiren, Ataga dan Thomas, 1986; Kone et al., 2014; Mohidin et al., 2015; Sulistiyanto, 2017).

\section{Jumlah dan Panjang Akar Primer}

Respon jumlah dan panjang akar bibit tanaman kelapa sawit main nursery umur 12 MST akibat pemberian kombinasi pupuk organik (pupuk petroganik dengan bokhasi kayambang) pada tanah gambut disajikan pada Gambar 3 dan 4.

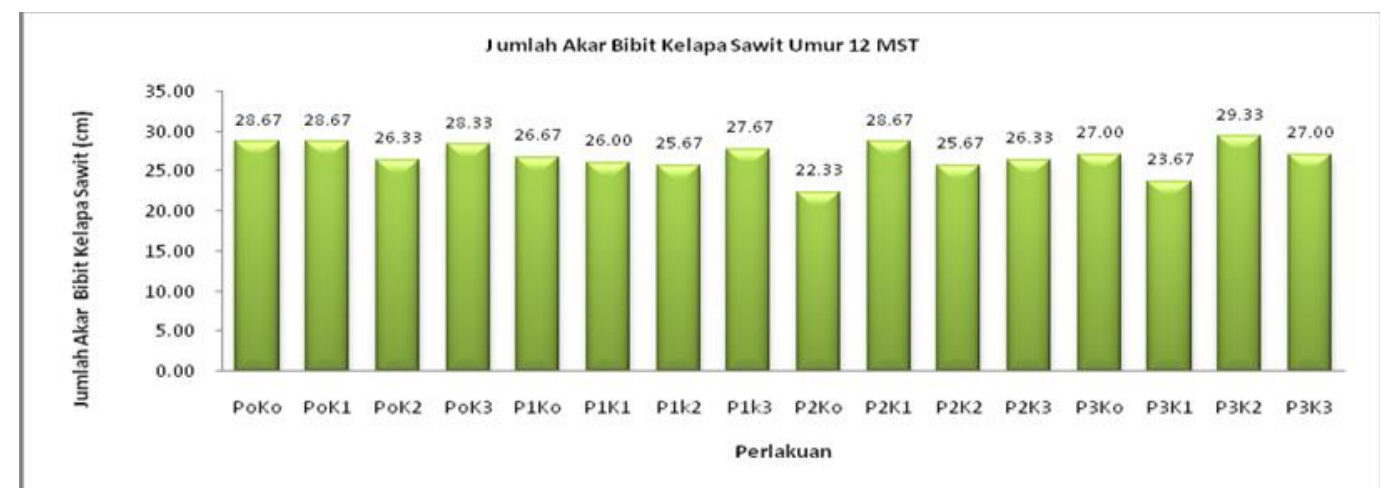

Gambar 3. Respon jumlah akar bibit kelapa sawit main nursery umur 12 MST akibat pemberian kombinasi pupuk petroganik dengan bokhasi kayambang 


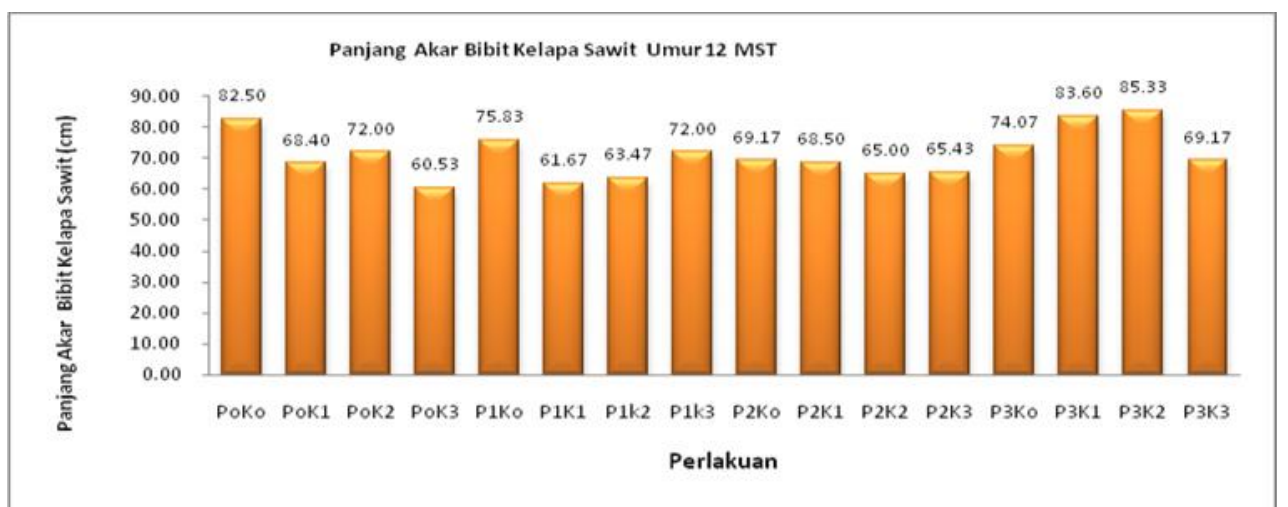

Gambar 4. Respon panjang akar bibit kelapa sawit main nursery umur 12 MST akibat pemberian kombinasi pupuk petroganik dengan bokhasi kayambang

Gambar 3 dan 4 menunjukkan bahwa perlakuan petroganik $2 \mathrm{~kg} / \mathrm{tanaman}$ dan Bokhasi Kayambang $1 \mathrm{~kg} / \operatorname{tanaman}$ (P3K2) menghasilkan jumlah akar terbanyak dan panjang akar terpanjang. Hal ini berarti bahwa pemberian pupuk petroganik dan bokhasi kayambang pada P3K2 relatif lebih mampu menyum-bangkan hara dalam pembentukan jumlah dan panjang akar bibit kelapa sawit main nursery umur $12 \mathrm{MST}$. Hal ini juga didukung nilai $\mathrm{pH}$ tanah akhir pada perlakuan P3K2 sebesar 5,95, berarti dengan nialai $\mathrm{pH}$ tersebut hara yang disumbangkan dari perlakuan P3K2 cukup mendukung pembentukan jumlah dan panjang akar bibit kelapa sawit main nursery pada umur 12 MST.

Pemberian pupuk organik (petroganik dan bokhasi kayambang) merupakan pupuk yang dapat digunakan untuk memperbaiki kesuburan dan kesehatan tanah yang ramah lingkungan. Pupuk petroganik memiliki spesifikasi kadar C - organik 12,5\%, C/N rasio $10-25, \mathrm{pH} 4-8$, dan kadar air $4-$ $12 \%$. Pupuk petroganik berfungsi untuk menggemburkan dan menyuburkan tanah, meningkatkan daya simpan dan daya serap air, memperkaya hara makro dan mikro serta sesuai untuk semua jenis tanah dan jenis tanaman (Pt. Aneka Jasa Gradika, 2008).

Penggunaan pupuk organik dapat memperbaiki karakteristik fiiska tanah, tanah menjadi lebih gembur, aerasi lebih baik dan mudah ditembus oleh akar tanaman (Herencia et al., 2011). Selain memperbaiki sifat fisik tanah pupuk organik juga memperbaiki sifat kimia tanah, yaitu dengan membantu proses pelapukan bahan mineral. Bahan organik juga memberikan makanan bagi kehidupan mikrobia dalam tanah (Anonim, 2010; Suatiyah dan Zubaidah, 2013; Sulistiyanto, 2017). Bokhasi kayambang dapat menyuburkan tanah karena $\mathrm{EM}_{4}$ yang dikandungnya secara fisik dapat menyuburkan tanah, lapisan olah tanah menjadi lebih dalam dan ruang gerak akar menjadi bertambah luas sehingga jumlah dan panjang akar tumbuh dengan baik. Secara kimia $\mathrm{EM}_{4}$ dapat meningkatkan $\mathrm{pH}$ tanah kearah netral, sehingga ketersediaan unsur hara menjadi semakin tinggi bagi perkaran tanaman. Dari segi biologi, $\mathrm{EM}_{4}$ dapat meningkatkan populasi mikro organisme fermentasi dan sintetik, pertumbuhan penyakit dan serangga dapat ditekan (Wididana, 1996; Deptan, 1997; Dara,1998, Sustiyah et al., 2015).

\section{KESIMPULAN}

\section{Kesimpulan}

1. Pemberian pupuk organik (petrogenik dan bokhasi kayambang) dapat meningkatkan pertumbuhan bibit kelapa sawit main nursery, diukur dari parameter tinggi tanaman, jumlah pelepah daun, jumlah akar dan panjang akar.

2. Pemberian pupuk petroganik 2 $\mathrm{kg} /$ tanaman dan bokhasi kayambang 1 $\mathrm{kg} /$ tanaman (Perlakuan P3K2) menghasilkan tanaman yang paling tinggi, pelepah daunnya paling banyak pada umur 1-12 MST, jumlah akar paling 
banyak dan akarnya paling panjang pada bibit umur 12 MST.

3. Perlakuan P3K2 mampu meningkatkan $\mathrm{pH}$ tanah menjadi 5,95.

\section{Saran}

1. Penelitian lanjutan perlu dilakukan untuk mengkaji dosis pupuk petrogenik dan bhokasi kayambang yang sesuai untuk tanah-tanah gambut pedalaman dengan memperhatikan kadar air pupuk organik, khususnya jika menggunakan perlakuan bokhasi kayambang.

Aplikasi pupuk bhokasi kayambang ke dalam tanah disarankan pada kondisi kadar air tanah kurang dari $25 \%$.

\section{DAFTAR PUSTAKA}

Afandi,F.N., B.Siswanto dan Y.Nuraini. 2015. Pengaruh pemberian berbagai jenis bahan organik terhadap sifat kimia tanah pada pertumbuhan dan produksi tanaman ubijalar di entisol Ngrangkah Pawon, Kediri. Jurnal Tanah dan Sumberdaya Lahan, 2(2): 237-244

Akpo, E., P.V.Vissoh, R.C.Tossou, T.A.Crane, D.K.Kossou, P.Richards, T.-J.Stomph, and P.C.Struik. 2012. A participatory diagnostic study of the oil palm (Elaeis guineensis) seed system in Benin. NJAS - Wageningen J. Life Sci. 60-63: 15-27.

Akpo,E., T.J.Stomph, D.K. Kossou, A.O.Omore and P.C. Struik. 2014a. Effects of nursery management practices on morphological quality attributes of tree seedlings at planting: The case of oil palm (Elaeis guineensis Jacq.). Forest Ecology and Management, 324: 28-36.

Akpoa,E., T.J.Stompha, D.K.Kossoub and P.C.Struik. 2014.Growth dynamics of tree nursery seedlings: The case of oil palm. Scientia Horticulturae, 175: 251257.

Al-Bataina,B.B., T.M.Young and E.Ranieri. 2016. Effects of compost age on the release of nutrients. International Soil and Water Conservation Research, 4(3): 230-236.

Anonim. 2010. Pupuk Alami.

http://images.redhr.multiply.multiplycontent.com/a ttachment/0/SK6dJwoKCqEAAH1 veLA1/P upuk\%20cair.doc?nmid=111721253.
BPS Kalteng. 2007. Kalimantan Tengah dalam Angka. Badan Pusat Statistik Kalimantan Tengah. Palangka Raya.

Cao, H.-X., Sun, C.-X., Shao, H.-B., Lei, X.T., 2011. Effects of low temperature and drought on the physiological and growth changes in oil palm seedlings. Afr. J. Biotechnol., 10: 2630-2637.

Chaves,B., S.De Neve, P.Boeckx, O.Van Cleemput and G.Hofman. 2007. Manipulating nitrogen release from nitrogen-rich crop residues using organic wastes under field conditions. Soil Science Society of America Journal, 71 (4): 1240

Dara,E.K. 1998. Seputar Teknologi $\mathrm{EM}_{4}$ (Efektifitas mikroorganisme). Dinas Pertanian Tanaman Pangan. Palangkaraya.

DeNeve,S. and G.Hofman. 1996. Modelling N mineralization of vegetable crop residues during laboratory incubations. Soil Biology and Biochemistry, 28 (1011): 1451-1457

DeNeve,S., S.G.Sáez, B.C.Daguilar, S.Sleutel and G.Hofman. 2004. Manipulating N mineralization from high $\mathrm{N}$ crop residues using on- and off-farm organic materials. Soil Biology and Biochemistry, 36(1): 127-134

Departemen Pertanian. 1997b. Teknologi Efektif Mikroorganisme $-4\left(\mathrm{EM}_{4}\right)$ pada Pertanian Ramah Lingkungan. Balai Pengkajian Tekonologi Pertanian. Palangkaraya.

Ghosh,S., B.Wilson, S.Ghoshal, N.Senapati and B.Mandal. 2012. Organic amendments influence soil quality and carbon sequestration in the IndoGangetic plains of India. Agriculture, Ecosystems and Environment, 156: 134-141.

Hai,L., X.G.Li, F.M.Li, D.R.Suo and G. Guggenberger. 2010. Long-term fertilization and manuring effects on physically-separated soil organic matter pools under a wheat-wheat-maize cropping system in an arid region of China. Soil Biology and Biochemistry, 42: 253-259.

Hakim. 1985. Evaluasi Kemampuan Lahan. Jurusan Ilmu Tanah Faperta IPB. Bogor.

Herencia,J.F., P.A.Garcia-Galavis and C. Maqueda. 2011. Long-Term Effect of 
Organic and Mineral Fertilization on Soil Physical Properties Under Greenhouse and Outdoor Management Practices. Pedosphere, 21(4): 443-453

Ibrahim,M.H., H.Z.E.Jaafar, M.H. Harun and M.R.Yusop. 2010. Changes in growth and photosynthetic patterns of oil palm (Elaeis guineensis Jacq.) seedlings exposed to short-term $\mathrm{CO}_{2}$ enrichment in a closed top chamber. Acta Physiol. Plant., 32(2): 305-331.

Iremiren,G.O., D.O. Ataga and G.O.Thomas. 1986. Frequencies of applying two fertilizer mixtures to polybag oil-palm seedlings. Fertilizer research, 10(3): 237-242.

Kone,B., W.A.Yte, D.Sekou, J.N.Konan, A.Koutou, K.E.Konan and M.Zouzou. 2014. Organic and mineral fertilization of Oil palm at the nursery stage. European Scientific Journal,10: 254268.

Kong, A.Y.Y, J. Six, D.C.Bryant, R.F.Denison and C.Van Kessel. 2005. The relationship between carbon input, aggregation, and soil organic carbon stabilization in sustainable cropping systems. Soil Science Society of America Journal, 69: 1078-1085.

Krystof,O., R.Andriani, H.Komanidin and A.Andrianto. 2012. Environmental and social impacts of oil palm plantations and their implications for biofuel production in Indonesia. Ecology and Society, 17(1): 25.

Lawenga,F.F., U.Hasanah dan D.Widjajanto. 2015. Pengaruh pemberian pupuk organik terhadap sifat fisika tanah dan hasiltanaman tomat (lycopersicum esculentum mill.) Di Desa Bulupountu Kecamatan Sigi Biromaru, Kabupaten Sigi. e-J. Agrotekbis $3(5): 564-570$

Lee,J. 2010. Effect of application methods of organic fertilizer on growth, soil chemical properties and microbial densities in organic bulb onion production. Scientia Horticulturae, 124(3): 299-305.

Liu,C.-A., F.-R.Li, L.-M.Zhou, R.-H.Zhang, Y.Jia, S.-L.Lin, L.-J.Wang, K.H.M. Siddique and F.-M.Li. 2013. Effect of organic manure and fertilizer on soil water and crop yields in newly-built terraces with loess soils in a semi-arid environment. Agricultural Water Management, 117: 123-132.
Liu,E., C.Yan, X.Mei, W.He, S.H.Bing, L.Ding, Q.Liu, S.Liu, T.Fan. 2010. Long-term effect of chemical fertilizer, straw, and manure on soil chemical and biological properties in northwest China. Geoderma, 158(3-4): 173-180.

Ludin,N.A., M.A.M.Bakri, N.Kamaruddin, K.Sopian, M.S.Deraman, N.H.Hamid, N.Asim and M.Y.Othman. 2014. Malaysian oil palm plantation sector: exploiting renewable energy toward sustainability production. Journal of Cleaner Production, 65: 9-15.

Maltas,A., R.Charles, B.Jeangros, S.Sinaj. 2013. Effect of organic fertilizers and reduced-tillage on soil properties, crop nitrogen response and crop yield: Results of a 12-year experiment in Changins, Switzerland. Soil and Tillage Research, 126: 11-18

Menšík, L., L.Hlisnikovský, L.Pospíšilová and E.Kunzová. 2018. The effect of application of organic manures and mineral fertilizers on the state of soil organic matter and nutrients in the long-term field experiment. Journal of Soils and Sediments, 18: 2813-2822.

Mohidin,H., M.M.Hanafi, Y.Mohd Rafii, S.N.A.Abdullah, A.S.Idris, S.Man, J.Idris and M.Sahebi. 2015. Determination of optimum levels of nitrogen, phosphorus and potassium of oil palm seedlings in solution culture. Bragantia, Campinas, 74(3): 247-254.

Munir,M. 1996. Tanah-Tanah Utama Indonesia: Karakteristik, Klasifikasi dan Pemanfaatannya. Pustaka Jaya. Malang.

Muslihat,L . 2009. Teknik Pembuatan Kompos Untuk Meningkatkan Produktivitas Tanah Dilahan Gambut. Co_ccfpi@wetlands.or.id

Nikoloyuk, J., Burns, T. R. and R.de Man. 2010. The promise and limitations of partnered governance: The case of sustainable palm oil. Corporate Governance, 10(1): 59-72.

Nuro,F., D.Priadi, dan E.S.Mulyaningsih. 2016. Efek pupuk organik terhadap sifat kimia tanah dan produksi kangkung darat (Ipomoea reptans Poir.). Prosiding Seminar Nasional Hasil-Hasil PPM IPB 2016. Hal : 2939. ISBN : 978-602-8853-29-3 
Ohimain,E.I. and S.C.Izah. 2014. Energy selfsufficiency of smallholder oil palm processing in Nigeria. Renewable Energy, 63: 426-431.

Oosterveer,P. 2015. Promoting sustainable palm oil: viewed from a global networks and flows perspective. Journal of Cleaner Production, 107: 146-153.

Pahan,I. 2006. Panduan Lengkap Kelapa Sawit Manajemen Agribisnis dari Hulu hingga Hilir. Penebar Swadaya. Jakarta.

Pt. Aneka Jasa Gradika. 2008. Buku Panduan Petroganik. Gresik.

Rahn,C.R., G.D.Bending, M.K.Turner and R.D.Lillywhite. 2003. Management of $\mathrm{N}$ mineralization from crop residues of high $\mathrm{N}$ content using amendment materials of varying quality. Soil Use and Management, 19(3): 193-200

Rong,Y., S.Yong-zhong, W.Tao and Y.Qin. 2016. Effect of chemical and organic fertilization on soil carbon and nitrogen accumulation in a newly cultivated farmland. Journal of Integrative Agriculture, 15(3): 658-666.

Rosmarkam,A. dan N.W. Yuwono. 2002. Ilmu Kesuburan Tanah. Kanisius. Yogyakarta.

Rudrappa,L., T.J.Purakayastha, D.Singh and S.Bhadraray. 2006. Long-term manuring and fertilization effects on soil organic carbon pools in a Typic Haplustept of semi-arid sub-tropical India. Soil and Tillage Research, 88: 180-192.

Ruskandi, 2006. Tenik pembuatan kompos limbah kebun pertamanan kelapa polikultur. Buletin Teknik Pertanian, 11(1): 1-3.

Setyamidjaja,D. 1991. Budidaya Kelapa Sawit. Penerbit Kanisius. Yogyakarta.

Su,Y.Z., F.Wang, D.R.Suo, Z.H.Zhang and M.W.Du. 2006. Long-term effect of fertilizer and manure application on soil-carbon sequestration and soil fertility under the wheat-wheat-maize cropping system in northwest China. Nutrient Cycling in Agroecosystems, 75: 285-295.

Sulistiyanto,Y. 2017. Dinamika Hara pada Hutan Rawa Gambut Teropika (3 ${ }^{\text {th }}$ Ed.). Kanisius. Yogyakarta.

Sustiyah dan S.Zubaidah. 2013. Pengaruh Limbah Padat Pabrik Pengolahan Karet terhadap Pertumbuhan Bibit Kelapa
Sawit pada Tanah Pasir. J. Agri Peat: 14:1:36-44.

Sustiyah, dkk. 2015. Pengaruh Pemberian Bokashi Kayambang terhadap Pertumbuhan Bibit Kelapa Sawit (Elaeis guineensis) pada Tanah Gambut. J. Agri Peat: 16:2: 95-106.

Teixeira, P.C., H.S.Rodrigues, W.A.A.Lima, R.N.C.Rocha, R.N.V.Cunha and R.Lopes. 2009. Container distribution and slow release fertilisers supply along the pre-nursery influencing oil palm seedlings growth. Ciência Florest., 19: 157-168.

Wididana,G.N., S.K.Riyatmo dan T.Higa. 1996. Tanya jawab teknologi efektif mikroorganisme. Koperasi Karyawan Dephut. Jakarta.

Willekens,K., B.Vandecasteele, D.Buchan, S. De Neve. 2014. Soil quality is positively affected by reduced tillage and compost in an intensive vegetable cropping system. Applied Soil Ecology, 82: 61-71

Yusof,B. 2007. Palm oil production through sustainable plantations. Eur J.Lipid Sci. Technol., 109: 289-295.

Zhao,Y., P.Wang, J.Li, Y.Chen, X.Ying and S.Liu. 2009. The effects of two organic manures on soil properties and crop yields on a temperate calcareous soil under a wheat-maize cropping system. European Journal of Agronomy, 31(1): 36-42.

Zhou,Z.C., Z.T.Gan, Z.P.Shangguan, F.P. Zhang. 2013. Effects of long-term repeated mineral and organic fertilizer applications on soil organic carbon and total nitrogen in a semi-arid cropland. European Journal of Agronomy, 45: 2026. 